\title{
Adjusting the Currency Composition of China's Foreign Exchange Reserve
}

\author{
Kai Shi ${ }^{1} \& \mathrm{Li} \mathrm{Nie}^{2}$ \\ ${ }^{1}$ School of Economics, Northeast Normal University, Changchun, China \\ ${ }^{2}$ Preparatory School for Chinese Students to Japan, Changchun, China \\ Correspondence: Kai Shi, School of Economics, Northeast Normal University, 2555 Jingyue Street, Changchun \\ 130117, P.R. China. Tel: 86-431-8453-6272.E-mail: shik142@nenu.edu.cn
}

\author{
Received: August 22, $2012 \quad$ Accepted: September 6, $2012 \quad$ Online Published: September 8, 2012 \\ doi:10.5539/ijef.v4n10p170 URL: http://dx.doi.org/10.5539/ijef.v4n10p170
}

\begin{abstract}
During the sovereign debt crisis, the national credit of some developed economic entities has been degraded repeatedly. It is adjusting the currency composition of China's foreign exchange reserve that becomes an important risk management tool. In this paper, we first make an analysis on possible currency composition of China's foreign exchange reserve combining data from the Treasury International Capital System of United States with IMF Currency Composition of Official Foreign Exchange Reserve, and then discuss the currency composition of minimum variance risk within the framework of Mean-Variance Analysis. Afterwards, a dynamic adjusting route from the real composition to the optimal structure is built up through the dynamic optimization approach. It is found that converting dollar assets to yen assets according to the optimal schedule will lower the risk of foreign exchange reserve effectively.
\end{abstract}

Keywords: foreign exchange reserve, currency composition, mean-variance analysis, dynamic optimization

\section{Introduction}

It is a consensus that the share of dollar assets in China's foreign exchange reserve is excessively high. Since 2002, the weak U.S. dollar against a basket of currencies has become increasingly obvious. Along with the continued accumulation, the loss of China's foreign exchange reserve caused by the devaluation of U.S. dollar and fluctuations in asset price attracts a lot of attention.

On February $5^{\text {th }}, 2010$, the State Administration of Foreign Exchange (SAFE) makes some improvements about the accounting principle of foreign exchange reserve: in Balance of Payments, the term of foreign exchange reserve will only record trading data; in the meanwhile, the value change of reserve assets irrelevant to transactions will reflect in International Investment Position. This change does not only get closer to the international practice, but also helps us recognize the loss of foreign exchange reserve.

Table 1. The value change of foreign exchange reserve and its sources

\begin{tabular}{|c|c|c|c|c|}
\hline & 2010 & $\begin{array}{c}\text { March, } \\
2011\end{array}$ & $\begin{array}{l}\text { June, } \\
2011\end{array}$ & $\begin{array}{l}\text { September, } \\
2011\end{array}$ \\
\hline $\begin{array}{l}\text { The change of foreign exchange reserve relative to the previous installment in } \\
\text { International Investment Position }\end{array}$ & 2800 & 1433 & 511 & -958 \\
\hline The shortfall of foreign exchange reserve in Balance of Payments & -4717 & -1412 & -1425 & -917 \\
\hline The change of reserve assets value related to non-trading factors & -1917 & 21 & -914 & -1875 \\
\hline
\end{tabular}

Notes: The shortfall of foreign exchange reserve in Balance of Payments = credit side - debit side, the negative value of shortfall shows that the foreign exchange reserve increases; Unit: a hundred million dollars.

According to the new accounting principle, the change of net reserve assets positions in International Investment Position consists of two separate parts: the first one is due to transactions; the other is caused by foreign exchange rate, asset prices and other non-trading factors. Clearly, except for the first quarter of 2011, China's foreign exchange reserve has been depreciating in most time, and the extent of devaluation in 2011 is more serious than that in 2010 . 
On May $6^{\text {th }}, 2011$, although one of the principals of SAFE presents the view in an interview that the appreciation of the renminbi will not cause the loss of foreign exchange reserve directly and reserve assets book surplus is far more than book loss, the loss caused by exchange rate change, fluctuations in asset price and other non-trading factors does exist.

In the post-crisis era, the voice about International Monetary System reform is getting bigger and stronger. The current International Monetary System is actually in the post-dollar and weak hegemony era. Although the security problem would not be solved thoroughly through the structure optimization about currency composition, it is still an effective approach to eliminate the risk of foreign exchange reserve.

In fact, there are three types of methods for managing currency composition. (Note 1) The most popular one is the Mean-Variance Analysis. The study of Ben-Bassat (1980) was the pioneer research to consider the currency composition of foreign reserves in mean-variance framework. Dellas and Yoo (1991) made the Mean-Variance Analysis important in the area of analyzing the currency composition of foreign reserves by proposing the difference between using the import share and the import currency share as weights of calculating the reference currency. The paper of Papaioannon et al. (2006) was one of the most comprehensive analyses on the optimal currency composition within this framework. Some literatures including Sheng and Zhao (2007), Liu (2008) and Zhang et al. (2010) did research on the currency composition of China's foreign exchange reserves, and others including Kong (2010) and Wang (2011) put forward their suggestions about the adjustment of currency composition. However, none of them pay enough attentions to the speed and proportion of adjustment.

In this paper, we will not stop in the stage of ascertaining the direction of adjustment. After the comparative analysis between possible practical currency composition of China's foreign exchange reserve based on available public statistic information, and the ideal minimum risk structure within Mean-Variance framework, an optimal adjusting route is set up through the dynamic optimization approach.

\section{A Currency Composition Analysis Based on TIC and COFER Data}

In China, all information about currency composition, investment classes and term structure of foreign exchange reserve is unpublished. For this reason, we are only allowed to make a sketch about possible currency composition of China's foreign exchange reserve. Here, we make a discussion combining data from U.S. Treasury International Capital System (TIC) with IMF Currency Composition of Official Foreign Exchange Reserve (COFER).

According to the Report on Foreign Holdings of U.S. Securities 2012, up to June $30^{\text {th }}$, 2012, the total holdings attributed to mainland China amount to 1.73 trillion dollar. The share of dollar assets in total reserve is about $55 \%$. However, it is unable to represent the actual dollar proportion in China's foreign exchange reserve for the next three following reasons: the first one is that TIC annual survey data are likely to underestimate China's investment in America (Setser and Pandey, 2009); the second one is that data from TIC referring to China's security investment in America include not only foreign exchange reserve but also the investment from other domestic institutions; the third one is that data from TIC comprise some investments that should not be included in foreign exchange reserve. (Note 2) The first factor is inclined to underestimate the actual proportion of dollar assets, while the last two are apt to overestimate it. In addition, it is more difficult to explore the shares of euro and yen assets.

Beyond this, as the biggest developing country in the world, the proportion of China's foreign exchange reserve in total holdings belonging to developing countries is relatively high. For this reason, data about the currency composition of emerging and developing countries foreign exchange reserve in COFER are also helpful for recognizing China's reserve composition. 


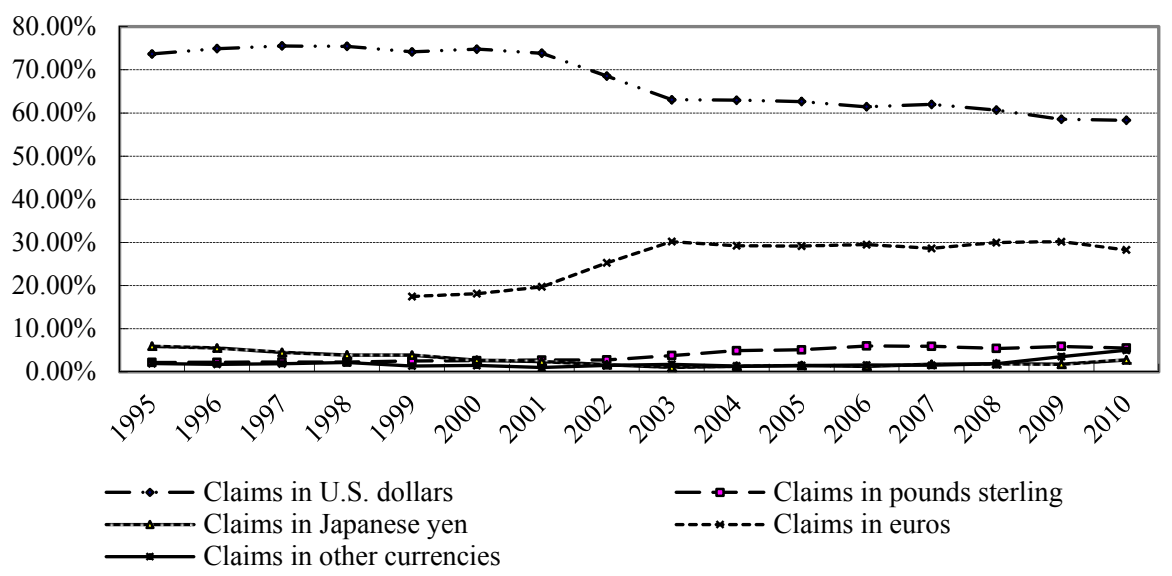

Figure 1. The currency composition of emerging and developing countries

According to COFER, the total proportion of four most major international currencies - dollar, euro, sterling pound and Japanese yen - in the currency composition of emerging and developing countries foreign exchange reserve exceeds $95 \%$. Since 2000, the share of dollar assets has been declining, varying from $75 \%$ in 1998 to less than $60 \%$ in 2010. In the meanwhile, since the day of its launch, the share of euro has been rising. After four years increasing, it has stabilized in the level of $30 \%$. Besides, neither sterling pound nor Japanese yen exceed $10 \%$. From 2002 to 2006 , the share of sterling pound continues to increase and has stabilized between $6 \%$ and 7\%. From 1995 to 2002, the share of Japanese yen drops significantly. Although there is a slight increase after the Subprime Crisis, it does not exceed 5\% yet. It is worth noting that the share of other currencies has been rising since 2008.

Combining TIC report with COFER data, we believe it is credible that China's foreign exchange reserve consists of $60 \% \sim 65 \%$ dollar, $25 \% \sim 30 \%$ euro, $5 \% \sim 7 \%$ sterling pound, and 3\% 5\% Japanese yen.

\section{The Minimum Variance Risk Currency Composition of China's Foreign Exchange Reserve}

After analyzing the actual structure of China's foreign exchange reserve, we focus on exploring the minimum variance risk currency composition within the framework of Mean-Variance Analysis.

The Mean-Variance Analysis on currency composition of foreign exchange reserve concerns about two aspects of risk and returns. It is believed that the utility of reserve assets depends on the value of its constituent financial assets denominated in some commodity basket and its variation. Because high returns are always accompanied by high risk, rational holders are not supposed to put all their fortunes in the only one currency assets of the highest returns. Similarly to Markowitz's portfolio theory, in Mean-Variance Analysis, the monetary authority is viewed as an investor, and the currency composition is regarded as asset portfolio. The aim of Mean-Variance Analysis is to pursue minimum variance risk. The main distinction lies in that the minimum risk point in efficient frontier is considered as the optimal portfolio due to the difficulty of determining the risk preference of monetary authority.

\subsection{Mean-variance Analysis on the Currency Composition of China's Foreign Exchange Reserve}

Let the expected returns vector of four major international currencies be $\mu=\left(\mu_{\text {usd }}, \mu_{\text {euro }}, \mu_{\text {pound }}, \mu_{\text {yen }}\right)^{\prime}$, the variance of expected returns be $\sigma^{2}=\left(\sigma_{u s d}^{2}, \sigma_{\text {euro }}^{2}, \sigma_{\text {pound }}^{2}, \sigma_{\text {yen }}^{2}\right)^{\prime}$, and the weight vector of four currencies be $X=\left(X_{u s d}, X_{\text {euro }}\right.$, $\left.X_{\text {pound }}, X_{\text {yen }}\right)^{\prime}$. Different from ordinary securities investors, safety and liquidity of reserve assets are the priority concerns. It is impossible for the monetary authority to hold short position. Thus, the weights of foreign exchange reserve currency composition need to meet the constraints:

$$
\sum_{i}^{N} X_{i}=1, X_{i} \geq 0, i=\text { usd, euro, pound, yen }
$$

In order to guarantee the security of reserve assets, it is necessary to pursue the minimum variance risk given the realized returns of foreign exchange reserve. The optimization model is as follows: 
$\min \frac{1}{2} \sigma_{p}^{2}=\frac{1}{2} X^{\prime} V X$

s.t.

$$
\left\{\begin{array}{l}
X^{\prime} \mu=\mu_{p}=\mu_{0} \\
X^{\prime} \mathbf{1}=\sum_{i} X_{i}=1 \\
X_{i} \geq 0, i=\text { usd, euro, pound, yen }
\end{array}\right.
$$

where $\mu_{p}$ and $\sigma_{p}^{2}$ stand for portfolio returns and variance, respectively, $V$ represents the variance-covariance matrix of asset returns, and $\mathbf{1}$ denotes a four dimensional column vector.

Papaioannon et al. (2006) point that the fundamental problem embedded in Mean-Variance Analysis lies in two aspects: firstly, it is difficult to estimate the returns of foreign exchange reserve accurately; secondly, it is hard to forecast the variance-covariance matrix. For the first problem, we consult the research of Zhang et al. (2010) about the nominal and real returns of China's foreign exchange reserve. Considering more general time-varying correlations, we employ DCC-GARCH model in forecasting the variance-covariance matrix.

\subsection{Empirical Results}

Within the framework of Mean-Variance Analysis, we consider to spread risk among four major international currencies, namely U.S. Dollar, Euro, Sterling Pound and Japanese Yen. For the convenience of comparative analysis, the total sample is divided into three sections according to the Subprime Crisis and $2^{\text {nd }}$ round Quantitative Easing policy (QE2).

Table 2. The optimal currency composition of minimum variance risk

\begin{tabular}{c|cccc|c}
\hline During the Subprime Crisis & U.S. Dollar & Euro & Sterling Pound & Japanese Yen & Minimum variance risk \\
\hline $3^{\text {rd }}$ Quarter, 2007 & $29.04 \%$ & $25.15 \%$ & $34.59 \%$ & $11.23 \%$ & 0.00001439 \\
$4^{\text {th }}$ Quarter, 2007 & $11.13 \%$ & $29.42 \%$ & $54.65 \%$ & $4.81 \%$ & 0.00002416 \\
$1^{\text {st }}$ Quarter, 2008 & $6.78 \%$ & $12.22 \%$ & $72.88 \%$ & $8.12 \%$ & 0.00024399 \\
$2^{\text {nd }}$ Quarter, 2008 & $16.42 \%$ & $63.04 \%$ & $15.20 \%$ & $5.35 \%$ & 0.01117763 \\
$3^{\text {rd }}$ Quarter, 2008 & $33.03 \%$ & $59.50 \%$ & $0.11 \%$ & $7.35 \%$ & 0.01808102 \\
\hline After the Subprime Crisis & U.S. Dollar & Euro & Sterling Pound & Japanese Yen & Minimum variance risk \\
\hline $4^{\text {th }}$ Quarter, 2008 & $41.88 \%$ & $43.29 \%$ & $10.46 \%$ & $4.38 \%$ & 0.12484435 \\
$1^{\text {st }}$ Quarter, 2009 & $49.62 \%$ & $34.17 \%$ & $6.34 \%$ & $9.87 \%$ & 0.17316376 \\
$2^{\text {nd }}$ Quarter, 2009 & $53.46 \%$ & $35.17 \%$ & $0.14 \%$ & $11.23 \%$ & 0.23217912 \\
$3^{\text {rd }}$ Quarter, 2009 & $52.33 \%$ & $29.18 \%$ & $4.18 \%$ & $14.31 \%$ & 0.23753490 \\
$4^{\text {th }}$ Quarter, 2009 & $52.83 \%$ & $31.27 \%$ & $7.23 \%$ & $8.67 \%$ & 0.30469038 \\
$1^{\text {st }}$ Quarter, 2010 & $53.34 \%$ & $27.35 \%$ & $6.29 \%$ & $13.02 \%$ & 0.35265724 \\
$2^{\text {nd }}$ Quarter, 2010 & $53.52 \%$ & $32.03 \%$ & $4.88 \%$ & $9.57 \%$ & 0.38165594 \\
$3^{\text {rd }}$ Quarter, 2010 & $55.25 \%$ & $26.58 \%$ & $4.88 \%$ & $13.30 \%$ & 0.36405214 \\
\hline During QE2 & U.S. Dollar & Euro & Sterling Pound & Japanese Yen & Minimum variance risk \\
\hline $4^{\text {th }}$ Quarter, 2010 & $55.04 \%$ & $33.67 \%$ & $2.93 \%$ & $8.37 \%$ & 0.35371175 \\
$1^{\text {st }}$ Quarter, 2011 & $55.26 \%$ & $32.17 \%$ & $2.24 \%$ & $10.33 \%$ & 0.34386967 \\
\hline
\end{tabular}

At least two key findings can be seen from empirical results: first, during the Subprime Crisis, in order to realize the minimum variance risk, the optimal shares of dollar, euro, pound assets varied significantly, while the share of Japanese yen assets stabilized between 5\% and 10\%; second, after the Subprime Crisis, the share of dollar assets is stable between $50 \%$ and $55 \%$, the share of euro is about $30 \%$, the share of pound fluctuates between $2 \%$ and $8 \%$, and the share of Japanese yen increases to between $7 \%$ and $15 \%$. 


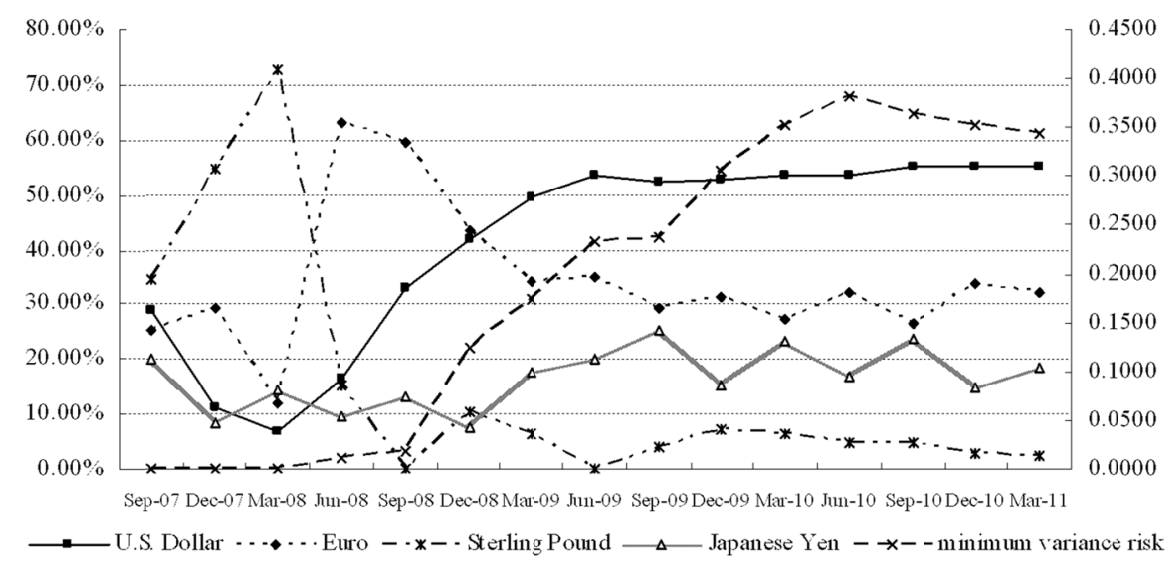

Figure 2. The currency composition of China's foreign exchange reserve and minimum risk

It is easily found that the change trend of dollar share is similar to the variation of minimum variance risk. The correlation coefficient is about 0.8916 . Obviously, the weakening of U.S. dollar as well as excessive proportion of dollar assets has become the important risk source implied in China's huge foreign exchange reserve.

\subsection{Discussions}

After the comparative analysis between the optimal and practical currency composition of China's foreign exchange reserve, there are at least two aspect works to do for risk control.

The first one is to lower the proportion of dollar assets in China's foreign exchange reserve. There is not much debate about American gloom economic outlook after the Subprime Crisis. Expansion fiscal policy and quantitative easing monetary policy are taken to stimulate economic recovery. Both of them result in global dollar flooding. Although hedge funds promote dollar to go strong in some stage, weakening dollar still brings down its real purchasing power and makes dollar assets less attractive. Since there is no dispute about the excessiveness of dollar proportion in China's foreign exchange reserve, it is imperative to reduce dollar assets share. Certainly, China's any activity about decreasing dollar assets should take global finance stability and the maintenance and increment of foreign exchange reserve value into account. Reducing dollar assets rashly may incur global finance market turmoil as well as more loss of foreign exchange reserve. Although Buffett praise China's foreign exchange reserve management policy, neither blind reduction nor continuing bulk-buying dollar assets is a wise choice. For China, it is more reasonable to focus on increment adjustment as well as stock conversion about mature assets. On the one hand, the authority should dilute dollar assets share through reducing purchase; on the other hand, they are encouraged to convert maturity dollar assets to non-dollar assets.

The second work is to expand the purchase of Japanese yen assets. As China's important trade partner, the Japanese yen assets have not been given enough attention. This may result from yen's incomplete internationalization as well as flagging Japanese economy. During the sovereign debt crisis, converting dollar assets to euro is definitely an unwise move. Clearly, it provides an opportunity for Japanese yen. The performance that China Investment Corporation purchases house property in Tokyo before the East Japan Earthquake maybe has revealed some new orientation of China's international reserve management. Besides, the post-disaster reconstruction theme is likely to push up Japanese yen. Thus, cutting down dollar assets as well as augmenting yen assets maybe lower the risk of China's foreign exchange reserve.

\section{The Dynamic Optimal Route of Dollar Assets Reduction}

Although decreasing dollar assets as well as increasing yen assets is helpful for lowering China's foreign exchange reserve risk, what really needs to be discussed, however, is the dynamic optimal route of dollar assets reduction.

\subsection{Fundamental Assumptions}

a. China's foreign exchange reserve consists of U.S. dollar, Euro, Sterling pound and Japanese yen assets. The euro assets proportion is about $28 \%$, and the pound assets share amounts to $5 \%$. Let the proportion of dollar assets equal to $\boldsymbol{x}$, and then the share of yen assets equals to $1-28 \%-5 \%-\boldsymbol{x}$, where $\boldsymbol{x}$ is the function of time $\boldsymbol{t}$.

$\boldsymbol{b}$. China's foreign exchange reserve increases following the pattern $W_{t}=W_{0} \cdot\left(\beta_{0}+\beta_{1} \cdot t+\beta_{2} \cdot t^{2}\right)$, where $W_{0}$ represents the initial scale. 
In order to explain its rationality, we make some empirical analyses about China's foreign exchange reserve growth through log-linear model, linear model and binomial model. The fitting results are as follows.

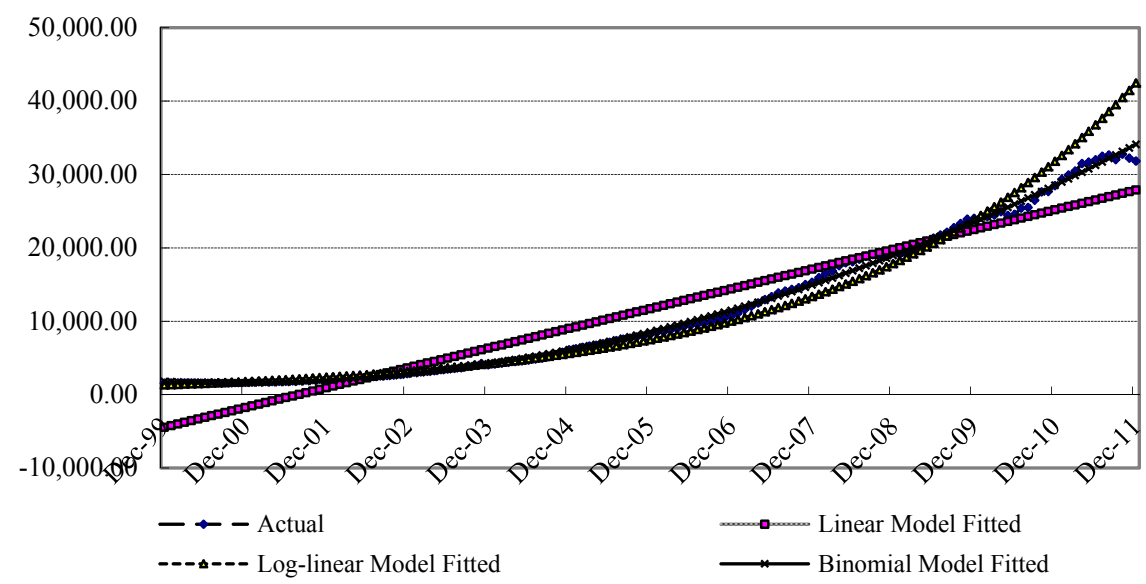

Figure 3. Foreign exchange reserve actual and fitted value

Comparative analysis illustrates that the binomial model describes China's foreign exchange reserve growth well. Thus, the setting about reserve growth is reasonable and acceptable.

c. The long-term average returns of dollar and yen assets equal to American and Japanese inflation rates, respectively.

Foreign exchange reserve is stored in abroad and denominated in foreign currency. Considering security, liquidity and market capacity, China's foreign exchange reserve is usually invested in high credit rating long-term treasury bonds. Thus, the returns of foreign exchange reserve are mainly related to treasury bond yields. Meanwhile, the direct loss of holding foreign exchange reserve involves domestic and foreign-related factors that affect reserve currency value: one is the domestic inflation of reserve currency country, and the other is the foreign exchange rate variation of reserve currency. It is generally accepted that the treasury bonds of advanced countries have inflation-protected function. It is not exaggerated to assume the real returns of long-term treasury bonds equal to the inflation rates so long as there are not severe inflations in the U.S. and Japan.

$\boldsymbol{d}$. Reserve assets value is measured by the real purchasing power of a basket of currencies. The purchasing power change of U.S. dollar against a basket of currencies is $\Delta p$, where $\Delta p<0$ denotes the devaluation of dollar.

$\boldsymbol{e}$. In order to lower the risk, the SAFE makes an adjustment about the currency composition of China's foreign exchange reserve, which is to reduce dollar assets, $x^{\prime}<0$, as well as to increase yen assets

\subsection{Basic Problem}

The aim of reserve assets currency composition adjustment is to convert dollar assets to yen assets. Thus, in the process of adjustment, the maximization about total foreign exchange reserve value is equivalent to the local optimization about dollar and yen assets.

Due to the assumption that investment returns of reserve assets equal to inflation rates, the value of reserve assets in time $\boldsymbol{t}$ denominated in the real purchasing power of a basket of currencies consists of two parts: the initial value and the value of newly-increased parts.

In time $\boldsymbol{t}$, the initial dollar and yen assets value $F R_{1}$ follows

$$
F R_{1}=W_{0} \cdot\left(x+x^{\prime}\right) \cdot(1+\Delta p)+W_{0} \cdot\left(1-28 \%-5 \%-x-x^{\prime}\right)
$$

where $\Delta p<0$ denotes the loss of U.S. dollar against a basket of currencies.

The increment reserve $F R_{2}$ equals to the derivative of $W_{t}$ to $t$

$$
F R_{2}=\frac{\partial W_{t}}{\partial t}=W_{0} \cdot\left(\beta_{1}+2 \cdot \beta_{2} \cdot t\right)
$$


Suppose there is such following linear relationship

$$
-\alpha \cdot x^{\prime}=c_{1} \cdot \Delta p+c_{2} \cdot\left(\beta_{1}+2 \cdot \beta_{2} \cdot t\right)+c_{3} \cdot x
$$

where $\alpha>0, c_{1}>0, c_{2}>0, c_{3}>0$ and $\Delta p<0$.

In fact, the adjusting speed $\boldsymbol{x}^{\prime}$ is related to the devaluation degree of dollar $\Delta p$, (Note 3) the proportion of newly-increased reserve $\left(\beta_{1}+2 \cdot \beta_{2} \cdot t\right)$ and current dollar share $\boldsymbol{x}$. When the dollar keeps stable, foreign exchange reserve grows rapidly, and the current dollar share is relatively high, the SAFE chooses to cut down dollar assets faster. (Note 4)

The reserve assets needed to be optimized follows that

$$
\begin{aligned}
F R\left(t, x, x^{\prime}\right) & =F R_{1}+F R_{2} \\
& =W_{0} \cdot\left(x+x^{\prime}\right) \cdot(1+\Delta p)+W_{0} \cdot\left(1-28 \%-5 \%-x-x^{\prime}\right)+W_{0} \cdot\left(\beta_{1}+2 \cdot \beta_{2} \cdot t\right) \\
& =W_{0} \cdot\left(x+x^{\prime}\right) \cdot\left(\lambda_{0}+\lambda_{1} \cdot x^{\prime}+\lambda_{2} \cdot t+\lambda_{3} \cdot x\right)+W_{0} \cdot\left(0.67-x-x^{\prime}\right)+W_{0} \cdot\left(\beta_{1}+2 \cdot \beta_{2} \cdot t\right)
\end{aligned}
$$

where $\lambda_{0}=1-c_{2} \cdot \beta_{1} / c_{1}, \lambda_{1}=-\alpha / c_{1}, \lambda_{2}=-2 \cdot c_{2} \cdot \beta_{2} / c_{1}$, and $\lambda_{3}=-c_{3} / c_{1}$.

The fundamental issue of foreign exchange reserve currency composition optimization is reconstructed as finding $\boldsymbol{x}$ to achieve reserve assets value maximization in time span $[0, \mathrm{~T}]$. (Note 5)

In order to deal with the time value of money, the forward reserve assets value is converted to the present value through a positive discount rate $\rho$.

In the process of actual reserve management, the usual practice of SAFE is to set the desired dollar assets share target. Thus, the foreign exchange reserve currency management can be expressed as

$$
\begin{aligned}
& \max \quad \Gamma[x]=\int_{0}^{T} F R\left(t, x, x^{\prime}\right) \cdot e^{-\rho \cdot t} d t \\
& \text { s.t. } \quad x(0)=x_{0}, \quad x(T)=x_{T}
\end{aligned}
$$

where $x_{0}$ and $x_{T}$ are exogenous, and $x_{0}>x_{T}>0$.

\subsection{The Solution}

Based on the above mentioned objective function, $F=F R\left(t, x, x^{\prime}\right) \cdot e^{-\rho \cdot t}$ produces the first-order derivatives

$$
\begin{aligned}
& F_{x}=W_{0} \cdot\left[\left(\lambda_{0}-1\right)+\left(\lambda_{1}+\lambda_{3}\right) \cdot x^{\prime}+\lambda_{2} \cdot t+2 \cdot \lambda_{3} \cdot x\right] \cdot e^{-\rho \cdot t} \\
& F_{x^{\prime}}=W_{0} \cdot\left[\left(\lambda_{0}-1\right)+2 \cdot \lambda_{1} \cdot x^{\prime}+\lambda_{2} \cdot t+\left(\lambda_{1}+\lambda_{3}\right) \cdot x\right] \cdot e^{-\rho \cdot t}
\end{aligned}
$$

and the second-order derivatives

$$
\begin{aligned}
& F_{x^{\prime} x^{\prime}}=2 \cdot \lambda_{1} \cdot W_{0} \cdot e^{-\rho \cdot t} \\
& F_{x x^{\prime}}=\left(\lambda_{1}+\lambda_{3}\right) \cdot W_{0} \cdot e^{-\rho \cdot t} \\
& F_{t x^{\prime}}=W_{0} \cdot\left[\left(\lambda_{0} \cdot \rho-\rho-\lambda_{2}\right)+2 \cdot \lambda_{1} \cdot \rho \cdot x^{\prime}+\lambda_{2} \cdot \rho \cdot t+\left(\lambda_{1}+\lambda_{3}\right) \cdot \rho \cdot x\right] \cdot e^{-\rho \cdot t}
\end{aligned}
$$

According to the Euler equation, the first-order necessary condition follows that

$$
-W_{0} \cdot\left[c-2 \cdot \lambda_{1} \cdot x^{\prime \prime}+2 \cdot \lambda_{1} \cdot \rho \cdot x^{\prime}+\left(\lambda_{2} \cdot \rho+\lambda_{2}\right) \cdot t+\left(\lambda_{1} \cdot \rho+2 \cdot \lambda_{3}\right) \cdot x\right] \cdot e^{-\rho \cdot t}=0
$$

where $c=\lambda_{0}-\lambda_{2}+\left(\lambda_{0}-1\right) \cdot \rho$. Accordingly, the explicit solution of $\boldsymbol{x}$ can be found through Eq. (10). (Note 6) Besides, it is easy to construct

$$
|D| \equiv\left|\begin{array}{cc}
F_{x^{\prime} x^{\prime}} & F_{x^{\prime} x} \\
F_{x x^{\prime}} & F_{x x}
\end{array}\right|
$$

and its two principal minors 


$$
\begin{aligned}
& \left|D_{1}\right| \equiv\left|F_{x^{\prime} x^{\prime}}\right|=F_{x^{\prime} x^{\prime}}=2 \cdot \lambda_{1} \cdot W_{0} \cdot e^{-\rho \cdot t}<0 \quad \lambda_{1}=-\frac{\alpha}{c_{1}}, \quad \alpha>0, \quad c_{1}>0 \\
& \left|D_{2}\right| \equiv\left|\begin{array}{ll}
F_{x^{\prime} x^{\prime}} & F_{x^{\prime} x} \\
F_{x x^{\prime}} & F_{x x}
\end{array}\right|=-W_{0}^{2} \cdot\left(\lambda_{1}-\lambda_{3}\right)^{2} \cdot e^{-2 \cdot \rho \cdot t}
\end{aligned}
$$

Apparently, the second-order Legendre condition of maximization is also satisfied.

To sum up, the solution of $x$ is the dynamic optimal dollar assets share that maximizes foreign exchange reserve value in $[0, T]$.

\subsection{Numerical Simulation}

In order to find out the specific steps of reserve currency composition adjustment, it is necessary to determine the structure parameters in growth pattern prior to analysis.

Thus, we first utilize quarterly foreign exchange reserve data from $4^{\text {th }}$ Quarter, 1999 to $4^{\text {th }}$ Quarter, 2011 for the parameter estimation. After the empirical analysis, we make such following settings: $W_{0}=32000, \beta_{0}=0.055470$, $\beta_{1}=-0.003966$, and $\beta_{2}=0.000498$.

In fact, Eq. (5) illustrates different attitudes of the SAFE to the devaluation degree of dollar, reserve increasing speed and current dollar assets proportion. Given different considerations about political purpose, policy target and government behavior, the SAFE would give those three factors different weights. In this paper, we make such following settings: $\alpha=1, c_{1}=1 / 3, c_{2}=50$, and $c_{3}=0.02$. In the meanwhile, the discount rate $\rho=3 \%$ is used. (Note 7)

The comprehensive analysis combining TIC report with COFER data shows that the U.S. dollar assets share in China's foreign exchange reserve maybe reach up to $65 \%$ by the end of June, 2011. For this reason, the initial dollar assets weight has been set to $x(0)=65 \%$. The policy goal of currency composition adjustment is to lower down dollar assets share to $55 \%$ till the end of 2012 , namely $x(6)=55 \%$.

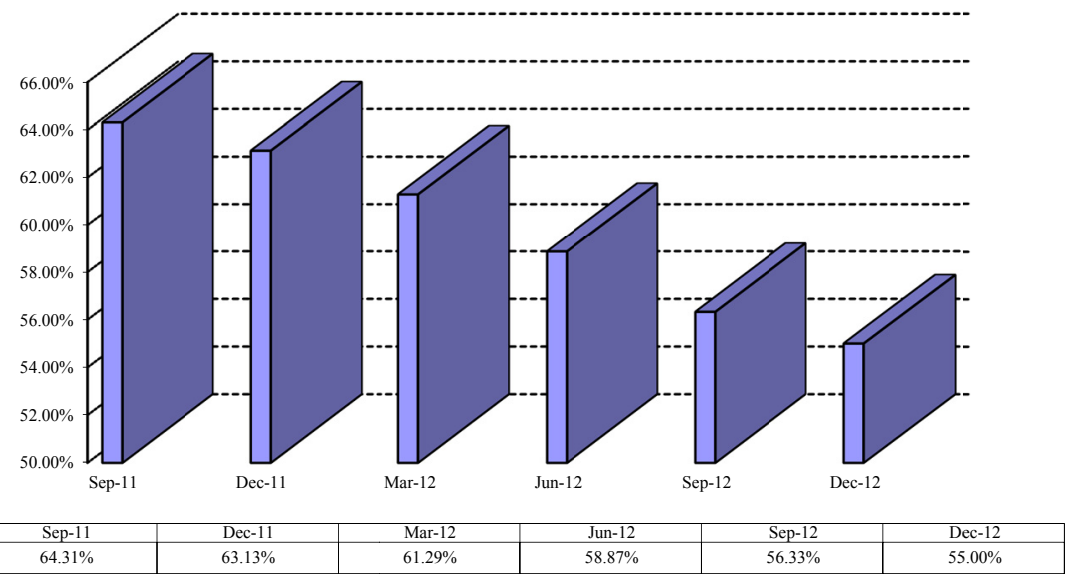

Figure 4. The optimal share of dollar assets

Figure 4 illustrates the dynamic optimal share of dollar assets in China's foreign exchange reserve, and Figure 5 presents the optimal route for cutting down dollar assets. According to 3.2 trillion dollar foreign exchange reserve scale, in order to achieve structure optimization, the SAFE should accomplish the net decreasing goal of at least 320 billion dollar from September, 2011 to December, 2012. The minimum decreasing scale is about 22.08 billion dollar, and the maximum decreasing scale reaches to 81.28 billion dollar. The average decreasing scale is about 53.33 billion dollar. 


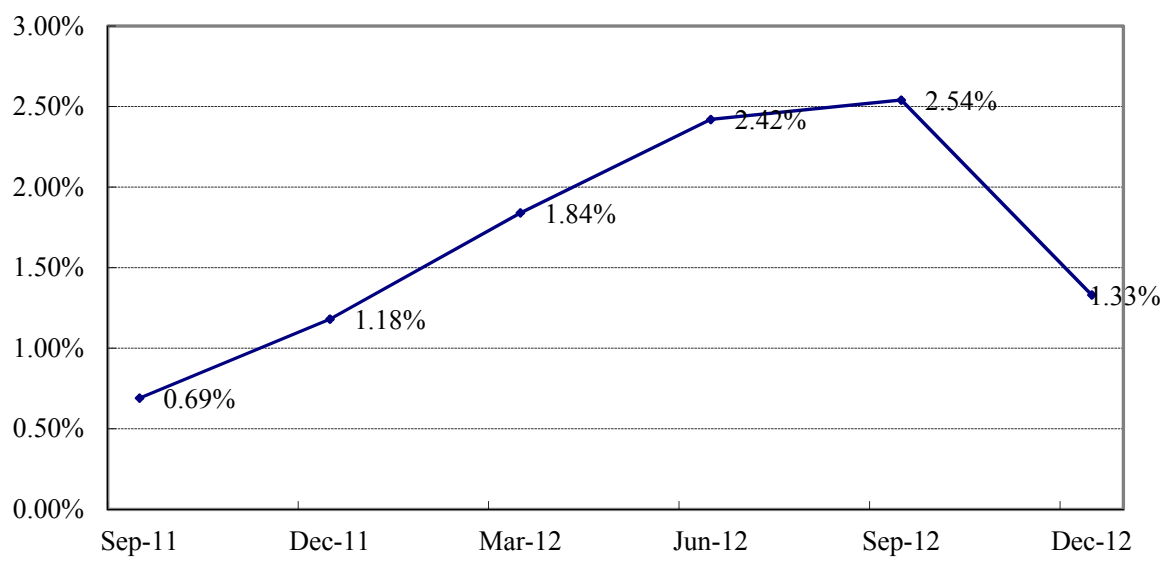

Figure 5. The proportion of decreasing dollar assets

During the adjusting process, the share of dollar assets does not decline linearly. The optimal reducing proportion displays the sickle-shaped feature.

\section{Conclusion}

Excessive dollar assets make the risk exposure of China's foreign exchange reserve bigger and bigger. The Report on Foreign Holdings of U.S. Securities shows that by June, 2007, all kinds of U.S. securities held by mainland China amounted to 922 billion dollar, including Freddie Mac and Fannie Mae debts 206 billion dollar and other asset-backed securities bonds 11 billion dollar. The proportion of Freddie Mac and Fannie Mae debts in total foreign exchange reserve reaches to $15.46 \%$. Once Freddie Mac and Fannie Mae being delisted, more than seventh of China's foreign exchange reserve is about to be worth nothing. Adjusting the currency composition is probably a more realistic and feasible way to manage foreign exchange reserve risk.

In post-crisis era, the instability of international monetary system strengthens significantly: the dollar still dominates, the euro faces challenges, and the pluralism is full of attractions. It is not beneficial for spreading risk to continue overweighting dollar assets. There are lots of problems in euro zone, thus it is unwise to increase euro assets under the circumstance of sovereign debts crisis. Although some scholars suggest that Asian countries should hold each other's currencies as their foreign exchange reserve (Fan et al., 2010), considering the depth of market and the degree of currency internationalization, it is difficult to lessen the risk of China's foreign exchange reserve following this way.

Within the framework of Mean-Variance Analysis, converting dollar assets to Japanese yen assets is a more realistic and effective way to maintain and increase foreign exchange reserve value. The statistics of international balance of payment jointly released by Japanese Ministry of Finance and Bank of Japan on June $4^{\text {th }}$, 2012, show that by the end of 2011, the Japanese treasury bonds held by China amount to 18 trillion yen (about 232.8 billion dollar) increasing about $71 \%$ over last year. The proportion of yen assets in China's foreign exchange reserve reaches up to the highest $7.27 \%$ in history. All of these show that China is accelerating the conversion of dollar assets against yen assets. The dynamic optimization analysis about decreasing dollar assets bridges the minimum variance risk structure and the practical currency composition of China's foreign exchange reserve, providing the authority a more realistic and effective adjusting route.

\section{Acknowledgements}

The authors are grateful to the financial supports from the Major Program of the National Social Science Foundation of China (Grant No. 10 \& ZD054); the Fundamental Research Funds for the Central Universities (11SSXT112); the Humanities \& Social Science Project supported by the MOE of China (No. 11YJC790181) and the Youth Item supported by NENU (2010QN009).

\section{References}

Ben-bassat, A. (1980). The Optimal Composition of Foreign Exchange Reserves. Journal of International Economics, 10, 285-295. http://dx.doi.org/10.1016/0022-1996(80)90059-8

Dellas, H., \& Yoo, C. (1991). Reserve Currency Preferences of Central Banks: the Case of Korea. Journal of International Money and Finance, 10, 406-419. http://dx.doi.org/10.1016/0261-5606(91)90018-F

Fan, G., Wang, B. Q., \& Huang, Y. P. (2010). Holding each other's currency: A Regional Cooperation 
Mechanism of Achieving Foreign Exchange Reserve Diversification. Report on Reserve Currency Diversification International Symposium, Beijing.

Kong, L. P. (2010). The Choice of Currency Composition of China's Foreign Exchange Reserve under International Financial Crisis. Studies of International Finance, 3, 64-72.

Liu, L. Y. (2008). Research on Change in Foreign Reserve Management Model form the Currency Composition and Yield in China. Journal of Finance and Economics, 7, 121-132.

Liu, S. G., \& Zhao, H. Y. (2007). Yields and Currency Composition of Foreign Reserves and Hot Money in China. China Economic Quarterly, Issue 4, pp. 1255-1276.

Papaioannou E., Portes R., \& Siourounis G. (2006). Optimal Currency Shares in International Reserves: the Impact of the Euro and the Prospects for the Dollar. Journal of the Japanese and International Economies, 20(4), 508-547. http://dx.doi.org/10.1016/j.jjie.2006.07.002

Setser, B., \& Pandey, A. (2009). China's \$1.5 Trillion Bet: Understanding China's External Portfolio. Council on Foreign Relations Working paper. from http://www.cfr.org/content/publications/attachments/CGS_WorkingPaper_6_China_update0509.pdf

Wang, Y. Z. (2011). The Composition, Yield and Risks of China's Foreign Exchange Reserve. Studies of International Finance, 1, 44-52.

Xu, Y. L., \& Zhang, Z. C. (2010). Foreign Exchange Reserve Currency Composition Management: A Review of International Studies. The Journal of World Economy, 9, 3-27.

Zhang, B., Wang, X., \& Hua, X. P. (2010). Nominal and Real Returns on China's Foreign Exchange Reserve. Economic Research Journal, 10, 115-128.

\section{Notes}

Note 1. Xu and Zhang (2010) made a detailed literature review on foreign exchange reserve currency composition management.

Note 2. For example, since 2007, domestic commercial banks are allowed to submit part of reserves against deposit in the form of foreign exchange. It should not be counted as national foreign exchange reserve, while it is included in TIC report.

Note 3. The adjusting speed equals to the derivative of dollar assets share $x$ to time $t, x^{\prime}=\partial x_{t} / \partial t$.

Note 4. In fact, we consider a reverse operation strategy. When the dollar keeps stable, it is easier to accomplish the transaction of cutting down dollar assets. In the meanwhile, to reduce the dollar assets selling will be helpful for stabilizing reserve assets value if coming across dollar turmoil.

Note 5. This is actually a problem of calculating the integral functional optimal value.

Note 6. Due to the existence of too many exogenous parameters, the explicit solution of $x$ is rather complicated. Thus, we do not pay much attention to it, but really focus on the following numerical simulation.

Note 7. In addition, we have tried different parameter settings. It is found that there are not big influences of $c_{1}$ and $c_{2}$ on the simulation results. Although the influence of $c_{3}$ on results is more significant, it does not change the fundamental trend of simulation results. It is clear that current dollar assets proportion should be given more attention in the process of foreign exchange reserve management. 